\title{
Cholesterol and stigmasterol within a sunflower oil matrix: thermal degradation and oxysterols formation
}

Blanca Barriuso, Diana Ansorena*, Candelaria Poyato, Iciar Astiasarán

Department of Nutrition, Food Science and Physiology, Faculty of Pharmacy, University of Navarra, C/ Irunlarrea s/n, 31008

Pamplona, Spain

bbarriuso@alumni.unav.es; mpoyato@alumni.unav.es; iastiasa@unav.es

* Corresponding author: email:dansorena@unav.es; telephone: 0034-948425600-6263 


\section{ABSTRACT}

The characteristics of the lipid matrix surrounding sterols exert a great influence in their thermal oxidation process. The objective of this work was to assess the oxidation susceptibility of equal amounts of cholesterol and stigmasterol within a sunflower oil lipid matrix (ratio 1:1:200) during heating ( $180{ }^{\circ} \mathrm{C}, 0$ to $180 \mathrm{~min}$ ). Remaining percentage of sterols was determined and seven sterol oxidation products (SOPs) were analyzed for each type of sterol along the heating treatment. Evolution of the fatty acid profile and vitamin E content of the oil was also studied. Overall oxidation status of the model system was assessed by means of Peroxide Value (PV) and TBARS. PV remained constant from 30 min onwards and TBARS continued increasing along the whole heating treatment. Degradation of both cholesterol and stigmasterol fitted a first order curve $\left(\mathrm{R}^{2}=0.937\right.$ and 0.883 , respectively), with very similar degradation constants $\left(0.004 \mathrm{~min}^{-1}\right.$ and $0.005 \mathrm{~min}^{-1}$, respectively). However, higher concentrations of oxidation products were found from cholesterol $(79 \mu \mathrm{g} / \mathrm{mg})$ than from stigmasterol $(53 \mu \mathrm{g} / \mathrm{mg})$ at the end of the heating treatment. Profile of individual oxidation products was similar for both sterols, except for the fact that no 25-hydroxystigmasterol was detected. 7 $\alpha$-hydroxy and 7-ketoderivatives were the most abundant SOPs at the end of the treatment. PUFA and vitamin E suffered a significant degradation along the process, which was correlated to sterols oxidation.

Keywords: sterols, vitamin E, polyunsaturated fatty acids 


\section{HIGHLIGHTS}

1. Cholesterol and stigmasterol fitted a first order degradation curve, with similar kinetic constants.

2. Higher concentrations of oxidation products were found from cholesterol than from stigmasterol.

3. Profile of individual oxidation products was similar for both sterols

4. PUFA and vitamin E degradation correlated to sterols oxidation.

\section{ABBREVIATIONS}

PV Peroxides Value

TBARS Thiobarbituric Acid Reactive Species

SOPs $\quad$ Sterol Oxidation Products

COPs Cholesterol Oxidation Products 
StOPs Stigmasterol Oxidation Products

PUFA Polyunsaturated Fatty Acids

MUFA Monounsaturated Fatty Acids

SFA Saturated Fatty Acids 


\section{Introduction}

Sterol oxidation products (SOPs) have been extensively reported to be involved in a variety of pathologies and diseases [1-4]. Their formation occurs endogenously both by enzymatic or non-enzymatic pathways, from sterols present in plasma and tissues [5].

Furthermore, sterol oxidation can also take place in foods before consumption [6]. In this issue, both cholesterol, as the main animal sterol, and plant sterols, which are used to enrich foods due to their hypocholesterolemic capacity, are susceptible to be oxidized in certain conditions, generating oxysterols. The incorporation of these exogenously formed oxysterols into the organism through the diet has been widely discussed. Although the intestinal absorption of these compounds (both from cholesterol and plant sterols) has been demonstrated [7-9], the relevance of phytosterol absorption versus endogenous formation of these compounds is still under debate, and some scientific evidence has been achieved [10-11]. So, assessment and control of factors affecting sterol oxidation in foodstuffs is a matter of interest for food safety purposes.

Among these influencing factors, processing, cooking and storage conditions clearly affect the oxysterols formation [12-14].

Furthermore, the presence of the surrounding lipids and their unsaturation degree exert some kind of effect, affecting the pattern of resulting oxidation products and also modulating the intensity and rate of oxidative reactions [15-18]. Additionally, both synthetic and natural antioxidants have presented promising results against sterol oxidation, being phenolic compounds and some vitamins some of the most studied compounds [19-20]. To study in detail all these influencing factors, model systems have been frequently used: from net model studies where only chemical standards are used as integrants of the experiments [16-17], often using stigmasterol as the 
plant sterol, to intermediate model systems, where chemical standards are mixed within foods [15, 20, 21]. This strategy allows isolating factors to be assessed, avoiding ambiguity from interferences among them. Thus, a deeper understanding of the underlying mechanisms is allowed and kinetic curves can be determined easily. Previous studies have been made in this regard, obtaining some mathematical models for sterols' degradation under thermal treatment, when they were heated alone and in the presence of pure triacylglycerols of increasing unsaturation degree [18, 22].

Considering all this, and taking into account that a combination of both animal and plant sterols can be found in foods intended for cholesterol-lowering purposes, the aim of the current study was to assess the thermal stability and oxidation susceptibility of a mixture of cholesterol and stigmasterol within a highly unsaturated oil (sunflower oil). The influence of both the saponifiable and unsaponifiable fractions of the oil on these processes was analyzed.

\section{Experimental}

\subsection{Reagents and materials}

Cholesterol, stigmasterol, 5 $\alpha$-cholestane, heptadecanoic acid, $\alpha$-tocopherol, tocopherol acetate, ammonium thyocianate and thiobarbituric acid were purchased from Sigma-Aldrich Chemical (Steinheim, Germany). 19-hydroxycholesterol was obtained from Steraloids (Wilton, NH, USA). Tri-sil ${ }^{\circledR}$ reagent was obtained from Thermo-Scientific (Rockford, IL, USA). Hexane, heptane, acetone, chloroform, ethyl acetate, butanol, methanol, 2-propanol, hydrochloric acid, cyclohexanone, trichloroacetic acid, potassium chloride, potassium hydroxide, ammonium iron (II) sulphate, barium chloride, anhydrous sodium sulphate and sodium phosphate were obtained 
from Panreac (Barcelona, Spain). Strata $\mathrm{NH}_{2}(55 \mu \mathrm{m}, 70$ A) $500 \mathrm{mg} / 3 \mathrm{~mL}$ Solid Phase Extraction cartridges were obtained from Phenomenex (Torrance, USA). Sunflower oil was purchased in a major local distributor.

\subsection{Heating process}

Cholesterol (30 mg), stigmasterol (30 mg) and sunflower oil (6 g) were solved in $25 \mathrm{~mL}$ of chloroform. Then, aliquots (1 mL) were placed in tubes and the solvent was evaporated under a gentle stream of $\mathrm{N}_{2}$. Tubes were then placed in a Tembloc (P Selecta, Spain) and heated at $180^{\circ} \mathrm{C}$ for $0,5,10,20,30,60,120$ and $180 \mathrm{~min}$. After each corresponding time, tubes were rapidly cooled down and each sample was solved in $1 \mathrm{~mL}$ chloroform and shaken vigorously. Samples were kept under $-20^{\circ} \mathrm{C}$ until analysis (except for Peroxides Value, that was determined immediately after heating). The experiment was performed in triplicate.

\subsection{Peroxides value}

Peroxides Value (PV) was analysed following the method of Shanta and Decker [23] with slight modifications. Briefly, an aliquot (50 $\mu \mathrm{L}$ ) of sample was transferred to a tube and chloroform was evaporated under a stream of $\mathrm{N}_{2}$. The residue was solved in $5 \mathrm{~mL}$ of a mixture butanol:methanol, (2:1). $\mathrm{SCNNH}_{4}(30 \%$ in distilled water, $25 \mu \mathrm{L})$ was added and tubes were vortexed for 4 s. Then, a solution of $\mathrm{FeCl}_{2}(36 \mathrm{mM}$ in $\mathrm{HCl}, 25 \mu \mathrm{L})$ was added and tubes were vortexed. After $15 \mathrm{~min}$, absorbance was measured at $510 \mathrm{~nm}$ in a FLUOStar Omega spectrofluorometric analyzer (BMG Labtechnologies, Offenburg, Germany). A calibration curve with Cumene hydroperoxide was done for quantification. Results were expressed as meq $\mathrm{O}_{2} / \mathrm{Kg}$ sample, being the data the average of 2 measurements per replicate $(n=6)$. 


\subsection{TBARS}

TBARS values were determined according to the method described by Poyato et al. [24]. Briefly, an aliquot (1 mL) of sample was transferred to a tube and chloroform was evaporated under a stream of $\mathrm{N}_{2}$. Distilled water $(0.5 \mathrm{~mL}), \mathrm{BHT}(20 \mu \mathrm{L}, 1 \%)$ and the TBARS reagent $(2 \mathrm{~mL})$ were vortexed, placed in a boiling water bath for $15 \mathrm{~min}$ and then cooled down in an ice bath to room temperature. Cyclohexanone $(4 \mathrm{~mL})$ and ammonium sulphate $(1 \mathrm{~mL}, 4 \mathrm{M})$ were added to the mixture and vortexed. The mixture was centrifuged at $1300 \mathrm{~g}$ for 10 minutes. The absorbance was measured at $532 \mathrm{~nm}$ in a FLUOStar Omega spectrofluorometric analyzer (BMG Labtechnologies, Offenburg, Germany). Results were expressed in mg of malondialdehyde (MDA) / Kg sample.

\subsection{Sterols determination}

An aliquot $(50 \mu \mathrm{L})$ of sample was transferred to a tube and chloroform was evaporated under a stream of $\mathrm{N}_{2}$. Cholesterol and stigmasterol determination was performed as described in Barriuso et al. [22], with slight modifications that only affected the chromatographic conditions applied. In this case, the equipment used was an Agilent 6890N-5975, a Column Varian VF-5ms CP8947 (50 m x $250 \mu \mathrm{m} \times 0.25 \mu \mathrm{m}$ ) with the oven conditions as follows: temperature started at $85^{\circ} \mathrm{C}$, increased to $290{ }^{\circ} \mathrm{C}$ at a rate of 50 ${ }^{\circ} \mathrm{C} / \mathrm{min}$, increased to $291^{\circ} \mathrm{C}$ at a rate of $0.05^{\circ} \mathrm{C} / \mathrm{min}$.

\subsection{Sterol oxidation products determination}

An aliquot $(800 \mu \mathrm{L})$ of sample was transferred to a tube and chloroform was evaporated under a stream of $\mathrm{N}_{2}$. 19-hydroxycholesterol ( $1 \mathrm{~mL}$ of $20 \mu \mathrm{g} / \mathrm{mL}$ in hexane:2-propanol, 3:2) was added as internal standard. Solid phase extraction (SPE) was performed for 
purification of SOPs as described in Ansorena et al.[18]. The sample solutions of cholesterol and stigmasterol oxidation products were derivatized to trimethylsilyl (TMS) ethers. Their chromatographic analysis, identification and quantification were performed according to the validated method of Menéndez-Carreño et al. [25]. Calibration curves of COPs were also used to quantify StOPs, as it has been demonstrated that the response factor obtained for cholesterol oxidation products are also valid for quantitative work regarding

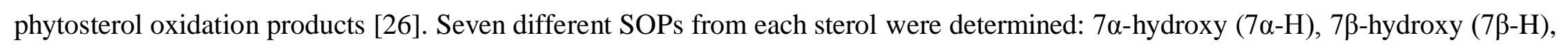

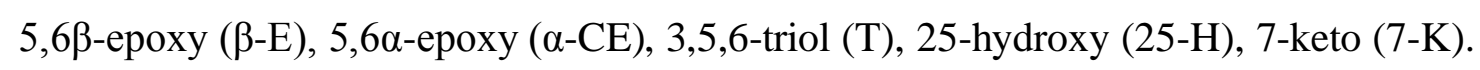

\subsection{Fatty acids determination}

An aliquot $(800 \mu \mathrm{L})$ of sample was transferred to a round bottom flask and chloroform was evaporated under a stream of $\mathrm{N}_{2}$. Fatty acid profile was obtained by gas chromatography FID detection, previous preparation of the fatty acid methyl esters, as described in Ansorena et al. [27].

\subsection{Vitamin E determination}

The $\alpha$-tocopherol $(\alpha-\mathrm{TOH})$ content was determined by HPLC-UV analysis according to the method described by Berasategi et al. [28]. Briefly, an aliquot $(800 \mu \mathrm{L})$ of sample was transferred to a volumetric flask and chloroform was evaporated under a stream of $\mathrm{N}_{2}$. $\alpha$ tocopherol acetate $(0.1 \mathrm{~mL}, 10 \mathrm{mg} / \mathrm{mL}$ solved in methanol) was added as internal standard and the flask was filled up to $10 \mathrm{~mL}$ with previously warmed $\left(30^{\circ} \mathrm{C}\right)$ supergradient HPLC grade methanol. Dilution was vortexed for $30 \mathrm{sec}$ and filtered with $0.20 \mu \mathrm{m}$ filter (Syringe-driven Filter Unit, Millex $\left.{ }^{\circledR}\right)$. The sample $(10 \mu \mathrm{L})$ was injected into the HPLC system and a isocratic elution with 
methanol/water (97:3) at $1.5 \mathrm{~mL} / \mathrm{min}$ flow was performed. UV spectra were recorded at $295 \mathrm{~nm}$ on a Perkin Elmer UV-Vis Lambda 200 Series equipped with a photodiode array detector Series 200 PDA, using an analytical precolumn $(3.8 \mathrm{~mm} \times 8 \mathrm{~mm}$ with $4 \mathrm{~mm} \times 3$ mm of C18 cartridges, Phenomenex, California, USA) and a LC18 column (150 mm x 3.9 mm, $4 \mu \mathrm{m}$ particle size; Waters).

Identification of $\alpha$-tocopherol was done using the retention time of the pure standard compound and its characteristic UV spectra. The quantification was performed using a calibration curve previously plotted with tocopherol acetate.

\subsection{Statistics}

For the statistical analysis of the data, Stata 12 program was used. Mean and standard deviation of data obtained from each replicate were calculated. One factor ANOVA, with Bonferroni's post hoc multiple comparisons $(p<0.05)$, was applied to evaluate the significant differences on sterols and SOPs amounts along heating time. t-Student was applied to evaluate the significant differences between cholesterol and stigmasterol data. For the mathematical modelling of cholesterol and stigmasterol degradation, the non-linear regression analysis was used. Correlations were assessed by Pearson’s correlation test.

\section{Results and discussion}

Overall oxidation status of samples at every point of analysis was assessed by means of both primary and secondary oxidation products (Figure 1). These methods inform about the presence of oxidation compounds originated both from the lipid matrix and the added sterols. Peroxides Value (PV) sharply increased, reaching a maximum at 30 min and maintaining a constant formation-degradation rate afterwards. The maximum value found (16 meq $\left.\mathrm{O}_{2} / \mathrm{Kg}\right)$ was significantly lower than that reported in a previous study [18] in which 
sterols were heated within unsaturated matrices lacking antioxidants (up to 40 meq $\mathrm{O}_{2} / \mathrm{Kg}$ ). On the other hand, TBARS values increased progressively along the whole heating process. Evolution of both parameters was the expected ones for oxidation processes.

\subsection{Sterol-structure effect}

Figure $2 \mathrm{a}$ showed the evolution of the remaining amounts of cholesterol and stigmasterol during heating. They both followed a very similar degradation pattern, fitting a first order curve $\left(\mathrm{R}^{2}=0.937\right.$ and 0.883$)$ with similar kinetic constants: [cholesterol] $=93.34 \mathrm{e}^{-0.004 \mathrm{t}}$ ; [stigmasterol] $=89.19 \mathrm{e}^{-0.005 \mathrm{t}}$. This pattern was also observed by Xu et al. [30], where cholesterol and sitosterol degraded equally under heating treatment. Despite this similar degradation rate during heating, some differences were noticed between the two sterols for the formation of their respective polar oxysterols (Figure 2b). Higher concentrations of oxidation products were found from cholesterol than from stigmasterol already after 60 min heating. After 180 min treatment, a similar percentage of cholesterol and stigmasterol were still remaining (around $40 \%$ ) and a difference of $30 \mu \mathrm{g} / \mathrm{mg}$ for oxysterols was detected. This is in accordance to previous works in model and food systems, where similar degradation rates had been noticed for different sterols, but higher amounts of COPs than of StOPs were found within the same experiment [22, 29]. Additionally, Xu and coworkers [30] reported slightly higher amounts of oxysterols from cholesterol than those from sitosterol after heating samples in several oil matrices.

Cholesterol and stigmasterol are structurally very similar, only differing in their side alkyl chain. Therefore, similar susceptibility to oxidation is expected for their 5, 6 and 7 ring-positions (which were the major oxidation sites found in this work, as it will be explained later). Lengyel et al. [31] calculated the enthalpy for $\mathrm{C}-\mathrm{H}$ bond breakage in position 7 and obtained exactly the same value 
for both sterols: $328 \mathrm{KJ} / \mathrm{mol}$. Nevertheless, a variety of other factors different than thermodynamics might be involved in the differential oxysterol formation from cholesterol compared to stigmasterol. Different kinetics, distinct dimers formation rate and steric hindrance of the molecule could be taken into account to explain these frequently found results.

\subsection{Oxysterols distribution}

Despite the different total amount of COPs and StOPs, the distribution and evolution pattern of individual oxidation products was similar for both sterols (Table 1). All oxysterols except for epoxides, increased their presence during heating, being 7-keto derivative the major one during the first stages of the treatment. After $30 \mathrm{~min}$, and simultaneously to the drastic vitamin E loss, a sharp increase of oxysterols was found, finding a maximum at 120 min heating. At this point, percentage of 43,40 and $15 \%$ for cholesterol derived compounds and 45, 38 and $17 \%$ for stigmasterol derived ones were achieved for 7-hydroxydes, epoxides, and 7-ketones, respectively. Although this is not an unusual distribution $[14,32]$, 7-keto derivatives are more frequently found as the major ones, mainly in advanced stages of oxidation. This point was also critical for epoxydes behavior, which started to decrease afterwards, with betaisomers being formed in higher amounts than alpha ones, as the steric hindrance of hydroxyl group in position 3 determines [33].

Oxysterols degradation after long-term high thermal treatments is commonly found. This behavior has been related to the formation of dimers and oligomers of varying polarity $[34,35]$. Regarding oxidation that affects the side chain, whereas a small content on $25-$ hydroxycholesterol could be noticed, no 25-hydroxystigmasterol was detected in the sample. Although the theoretically calculated enthalpies for C25 would indicate a more labile bond for stigmasterol than for other sterols (and the subsequent higher formation of 
25-hydroxycholesterol) [31], no formation of this compound under heating conditions of stigmasterol solved in vegetable oils has been previously reported [15].

\subsection{Surrounding matrix effect}

The effect of the lipid matrix on sterols oxidation is dependant on temperature and experimental conditions [36]. So, to study the effect of the sunflower oil towards cholesterol and stigmasterol oxidation, data of a previous study performed in the same experimental conditions but without any lipid surroundings were considered [22]. Sterols heated alone suffered a more intense degradation than within the sunflower oil matrix. After 5 min treatment, the percentages of remaining cholesterol were 60 and $90 \%$ in absence and presence of sunflower oil, respectively. Considering stigmasterol results, 50 and $90 \%$ of the initial sterol content remained in same conditions. On the other hand, oxysterols were formed much faster when sterols were heated alone, reaching after 5 min heating similar values than after $180 \mathrm{~min}$ in the presence of sunflower oil. The amount of oxysterols formed was, after $10 \mathrm{~min}, 79 \mathrm{Vs} 4 \mu \mathrm{g}$ COPs / mg cholesterol and $51 \mathrm{Vs} 7 \mu \mathrm{g}$ StOPs / mg stigmasterol for sample alone Vs sample within sunflower oil.

The protective effect of the lipid surrounding matrix to sterol oxidation was also described by Ansorena et al. [18], using pure triacylglycerols, and by Yen and co-workers [37, 38], who reported that cholesterol was oxidized more slowly within lard than alone. This behavior could be related to dilution of the sample, physical protection or competition for oxygen of the surrounding lipids [39]. Furthermore, vitamin E content of the sunflower oil could also be behind this protective effect against the sterol oxidation. In this sense, Xu et al. (2009) attributed to tocopherol the slower oxidation rate of both cholesterol and $\beta$-sitosterol in the presence of corn and 
olive oil. In our work, vitamin E was rapidly affected by heating, being lost already a $17 \%$ after 5 min treatment, and continued dropping until a $80 \%$ loss after $180 \mathrm{~min}$ (Table 2). This table also reported the evolution of fatty acids along treatment. Linoleic, the most abundant one in sunflower oil, decreased significantly from the first 10 min of treatment, and a $36 \%$ loss was noticed at the end of the heating process. Modification of the rest of fatty acids was less noticeable from the quantitative standpoint.

Figure 3 plotted the evolution during heating of both sterols (Fig 3a) and their oxides (Fig 3b) along with the evolution of the vitamin $\mathrm{E}$ and the main lipid fractions [total polyunsaturated fatty acids (PUFA), total monounsaturated fatty acids (MUFA) and total saturated fatty acids (SFA)]. Correlation coefficients among these curves were calculated (Table 3). These data indicated that the highest correlation values for cholesterol and stigmasterol were obtained for PUFA (0.94 and 0.93), followed by vitamin E ( 0.85 and 0.89). MUFA behavior did not correlate with sterol degradation as these fatty acids only suffered a small degradation from 10 min, and neither SFA correlated as they remained practically stable along time. The same trend was observed for total COPs and StOPs (Figure $3 \mathrm{~b}$ and Table 3): their formation was highly correlated to PUFA and vitamin E degradation.

In conclusion, when heated within sunflower oil at $180^{\circ} \mathrm{C}$, cholesterol and stigmasterol presented a very similar degradation pattern. Although a similar distribution of individual oxides was noticed, higher values of total oxysterols from cholesterol than from stigmasterol were observed at the end of the heating treatment. The oil matrix protected sterols from oxidation, with vitamin E and PUFA content playing a relevant role in this issue. 


\section{Acknowledgements}

We thank to "Plan de Investigación Universidad de Navarra" (PIUNA) for the finantial support. B. Barriuso is grateful to "Asociación de Amigos de la Universidad de Navarra" for the grant received. We thank Gwenaëlle Ceniceros for the technical assistance.

\section{References}

[1] Vejux A, Malvitte L, Lizard G. (2008). Side effects of oxysterols: cytotoxicity, oxidation, inflammation, and phospholipidosis. Brazilian Journal of Medical and Biological Research, 41(7), 545-556.

[2] Björkhem I, Cedazo-Minguez A, Leoni V, Meaney S. (2009). Oxysterols and neurodegenerative diseases. Molecular Aspects of Medicine, 30(3), 171-179.

[3] Vanmierlo T, Husche C, Schött HF, Pettersson H, Lütjohann D. (2013). Plant sterol oxidation products - Analogs to cholesterol oxidation products from plant origin? Biochimie, 95(3), 464-472.

[4] O’Callaghan Y, McCarthy FO, O’Brien NM (2014). Recent advances in Phytosterol Oxidation Products. Biochemical and Biophysical Research Communications, 446(3), 786-791. 
[5] Iuliano L. (2011). Pathways of cholesterol oxidation via non-enzymatic mechanisms. Chemistry and Physics of Lipids, 164(6), 457468.

[6] Otaegui-Arrazola A, Menéndez-Carreño M, Ansorena D, Astiasarán I, (2010). Oxysterols: A world to explore. Food and Chemical Toxicology, 48(12), 3289-3303.

[7] Meynier A, Andre A, Lherminier J, Grandgirard A, Demaison L, Andre, A, Lherminier, J, Grandgirard A, Demaison L. (2005). Dietary oxysterols induce in vivo toxicity of coronary endothelial and smooth muscle cells. European Journal of Nutrition, 44(7), 393405.

[8] Staprans I, Pan XM, Rapp JH, Feingold KR. (2005). The role of dietary oxidized cholesterol and oxidized fatty acids in the development of atherosclerosis. Molecular Nutrition \& Food Research, 49(11), 1075-1082.

[9] Leonarduzzi G, Sottero B, Poli, G. (2002). Oxidized products of cholesterol: dietary and metabolic origin, and proatherosclerotic effects (review). The Journal of Nutritional Biochemistry, 13(12), 700-710. 
[10] Bang H, Arakawa C, Takada M, Sato M, Imaizumi K. (2008). A comparison of the potential unfavorable effects of oxycholesterol and oxyphytosterol in mice: different effects, on cerebral 24S-hydroxychoelsterol and serum triacylglycerols levels. Bioscience, Biotechnology, and Biochemistry, 72(12), 3128-33.

[11] Baumgartner S, Mensink R, Husche C, Lütjohann D, Plat J. (2013). Effects of plant sterol- or stanol-enriched margarine on fasting plasma oxyphytosterol concentrations in healthy subjects. Atherosclerosis, 227(2), 414-9.

[12] Boselli E, Rodriguez-Estrada MT, Ferioli F, Caboni MF, Lercker G. (2010). Cholesterol photosensitised oxidation of horse meat slices stored under different packaging films. Meat Science, 85(3), 500-505.

[13] Lira GM, Barros Silva KW, Figueirêdo BC, Bragagnolo N. (2014). Impact of smoking on the lipid fraction and nutritional value of seabob shrimp (Xiphopenaeus kroyeri, Heller, 1862). LWT - Food Science and Technology, 58(1), $183-187$.

[14] Hernandez-Becerra JA, Ochoa-Flores A, Soto-Rodriguez I, Rodríguez-Estrada MT, García H.(2014) Effect of cooking conditions on cholesterol oxidation and astaxanthin in dried salted shrimp. European Journal of Lipid Science and Technology, 116(7), 872-884.

[15] Oehrl L, Hansen AP, Rohrer CA, Fenner GP, Boyd LC. (2001). Oxidation of phytosterols in a test food system. Journal of the American Oil Chemists' Society, 78(11), 1073-1078. 
[16] Lehtonen M, Lampi A, Riuttamaki M, Piironen V. (2012). Oxidation reactions of steryl esters in a saturated lipid matrix. Food Chemistry, 134(4), 2030-2039.

[17] Xu GH, Sun JL, Liang YT, Yang C, Chen ZY. (2011). Interaction of fatty acids with oxidation of cholesterol and beta-sitosterol. Food Chemistry, 124(1), 162-170.

[18] Ansorena D, Barriuso B, Cardenia V, Astiasarán I, Lercker G, Rodriguez-Estrada M (2013). Thermo-oxidation of cholesterol: Effect of the unsaturation degree of the lipid matrix. Food Chemistry, 141(3), 2757-64.

[19] Kmiecik D, Korczak J, Rudzinska M, Kobus Cisowska J, Gramza Michalowska, A. (2011). beta-Sitosterol and campesterol stabilisation by natural and synthetic antioxidants during heating. Food Chemistry, 128(4), 937-942.

[20] Polak T, Zlender B, Lusnic M, Gasperlin L, Žlender B, Lušnic M, Gašperlin, L. (2011). Effects of coenzyme Q10, a-tocopherol and ascorbic acid on oxidation of cholesterol in chicken liver pâté. Food Science \& Technology, 44(4), 1052-1058.

[21] Tabee E, Azadmard-Damirchi S, Jagerstad M, Dutta P. (2008). Effects of alpha-tocopherol on oxidative stability and phytosterol oxidation during heating in some regular and high-oleic vegetable oils. Journal of the American Oil Chemists' Society, 85(9), 857-867. 
[22] Barriuso B, Otaegui-Arrazola A, Menéndez-Carreño M, Astiasarán I, Ansorena D. (2012). Sterols heating: degradation and formation of their ring-structure polar oxidation products. Food Chemistry, 135(2), 706-12.

[23] Shantha N, Decker E. (1994). Rapid, sensitive, iron-based spectrophotometrhic methods for determination of peroxide values of food lipids. Journal of AOAC International, 77(2), 421-424.

[24] Poyato C, Navarro-Blasco I, Calvo MI, Cavero RY, Astiasarán I, Ansorena D. (2013). Oxidative stability of O/W and W/O/W emulsions: Effect of lipid composition and antioxidant polarity. Food Research International, 51(1), 132-140.

[25] Menéndez-Carreño M, García-Herreros C, Astiasarán I, Ansorena D. (2008). Validation of a gas chromatography-mass spectrometry method for the analysis of sterol oxidation products in serum. Journal of Chromatography.B, 864(1-2), 61-68.

[26] Apprich S, Ulberth F. (2004) Gas chromatographic properties of common cholesterol and phytosterol oxidation products. Journal of Chromatography A, 1055 (1-2), 169-176.

[27] Ansorena D, Echarte A, Ollé R, Astiasarán I. (2013). 2012: No trans fatty acids in Spanish bakery products. Food Chemistry, $138(1), 422-429$. 
[28] Berasategi I, Barriuso B, Ansorena D, Astiasarán I (2012). Stability of avocado oil during heating: Comparative study to olive oil. Food Chemistry, 2012, 132(1), 439-446.

[29] Menéndez-Carreño M, Ansorena D, Astiasarán, I. (2008). Stability of Sterols in Phytosterol-Enriched Milk under Different Heating Conditions. Journal of Agricultural and Food Chemistry, 56(21), 9997-10002.

[30] Xu G, Guan L, Sun J, Chen Z. (2009). Oxidation of cholesterol and beta-sitosterol and prevention by natural antioxidants. Journal of Agricultural and Food Chemistry, 57(19), 9284-9292.

[31] Lengyel J, Rimarcik J, Vaganek A, Fedor J, Lukes V. (2012). Oxidation of sterols: Energetics of C-H and O-H bond cleavage. Food Chemistry, 133(4), 1435-1440.

[32] Julien-David D, Zhao M, Geoffroy P, Miesch M, Raul F, Aoude-Werner D, Ennahar, S, Marchioni E. (2014). Analysis of sitosteryl oleate esters in phytosterols esters enriched foods by HPLC-ESI-MS2. Steroids, 84(0), 84-91.

[33] Lampi A, Juntunen L, Toivo J, Piironen V. (2002). Determination of thermo-oxidation products of plant sterols. Journal of Chromatography $B, 777(1-2), 83-92$. 
[34] Struijs K, Lampi A, Ollilainen V, Piironen V. (2010). Dimer formation during the thermo-oxidation of stigmasterol. European Food Research and Technology, 231(6), 853-863.

[35] Sosińska E, Przybylski R, Aladedunye F, Hazendonk P. (2014). Spectroscopic characterisation of dimeric oxidation products of phytosterols. Food Chemistry, 151(0), 404-414.

[36] Soupas L, Juntunen L, Lampi AM, Piironen V. (2004). Effects of sterol structure, temperature, and lipid medium on phytosterol oxidation. Journal of Agricultural and Food Chemistry, 52(21), 6485-6491.

[37] Yen TY, Lu Y, Inbaraj BS, Chen B. (2011). Cholesterol oxidation in lard as affected by CLA during heating - a kinetic approach. European Journal of Lipid Science and Technology, 113(2), 214-223.

[38] Yen T, Inbaraj B, Chien J, Chen B. (2010). Gas chromatography-mass spectrometry determination of conjugated linoleic acids and cholesterol oxides and their stability in a model system. Analytical Biochemistry, 400(1), 130-138.

[39] Rodríguez-Estrada MT, Garcia-Llatas G, Lagarda MJ (2014). 7-Ketocholesterol as marker of cholesterol oxidation in model and food systems: When and how. Biochemical and Biophysical Research Communications, 446(3), 792-797. 


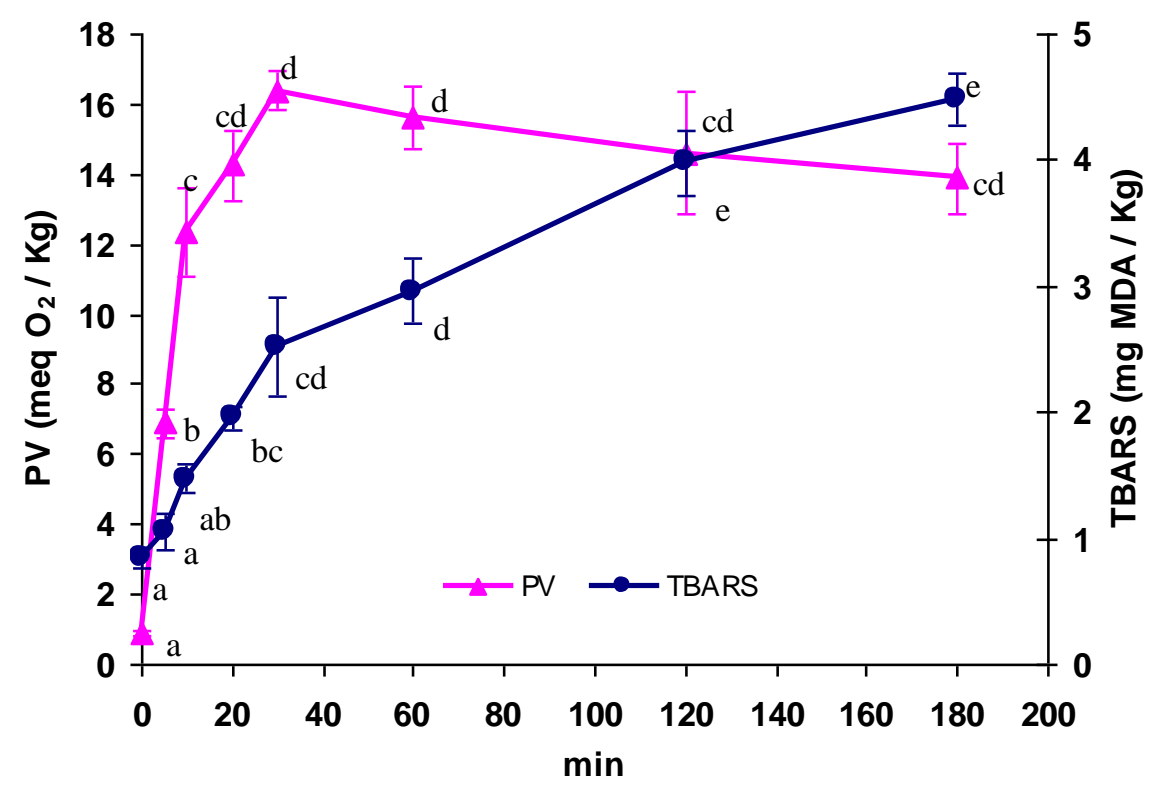

Figure 1. Peroxides Value meq $\mathrm{O}_{2} / \mathrm{Kg}$ and TBARS (mg MDA / Kg) along the heating process. Different letters for each parameter denote statistical differences $(\mathrm{p}<0.05)$ along time. 
a)

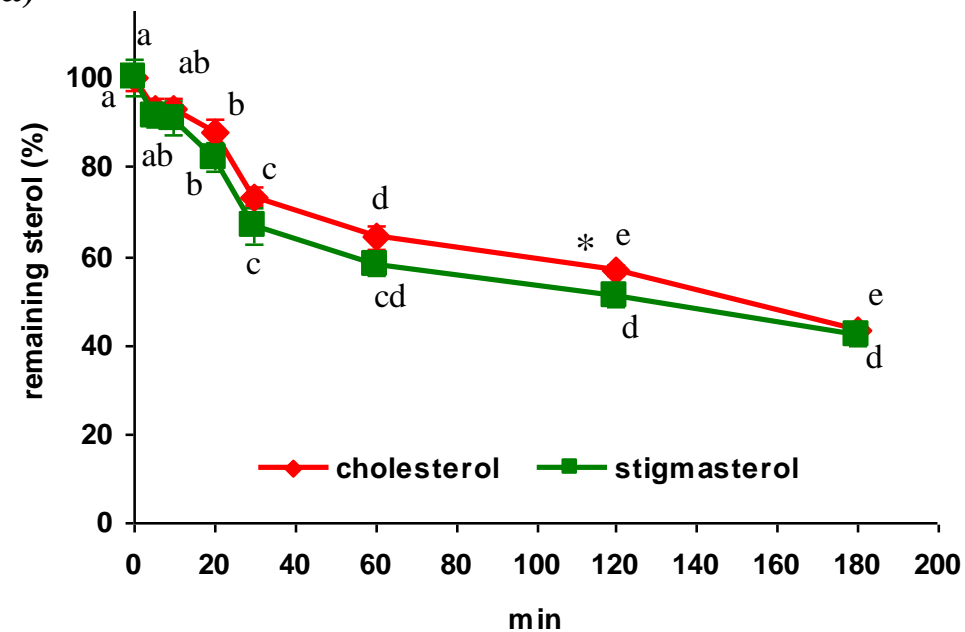

b)

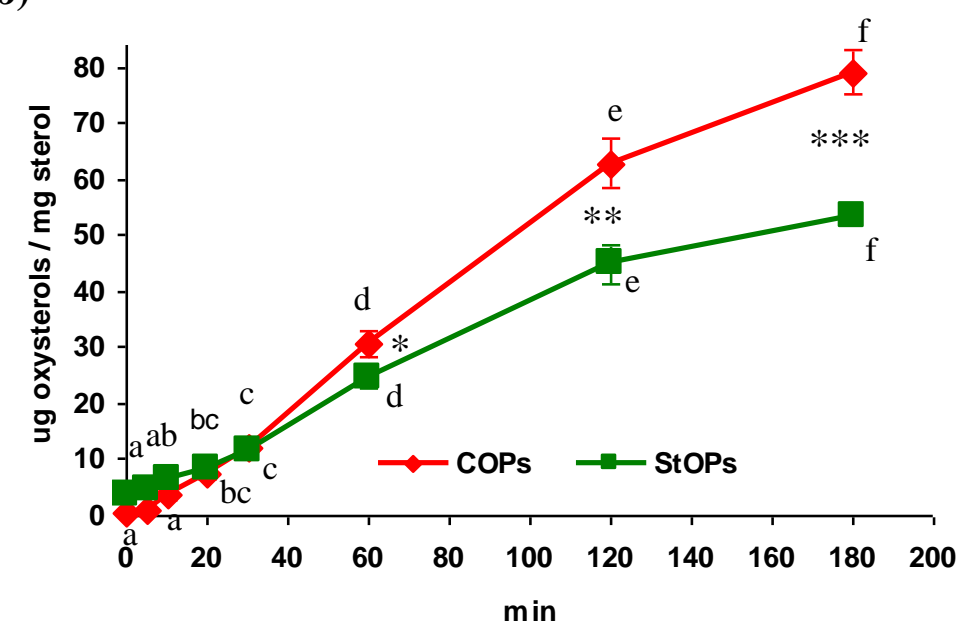

Figure 2. Remaining sterols (a) and content on total oxysterols (b) along the heating process. Different letters denote statistical differences $(\mathrm{p}<0.05)$ along time. $\mathrm{t}$ Student test compared stigmasterol and cholesterol (and their oxysterols) at every time of analysis $(* \mathrm{p}<0.05 ; * * \mathrm{p}<0.01 ; * * * \mathrm{p}<0.001)$. 

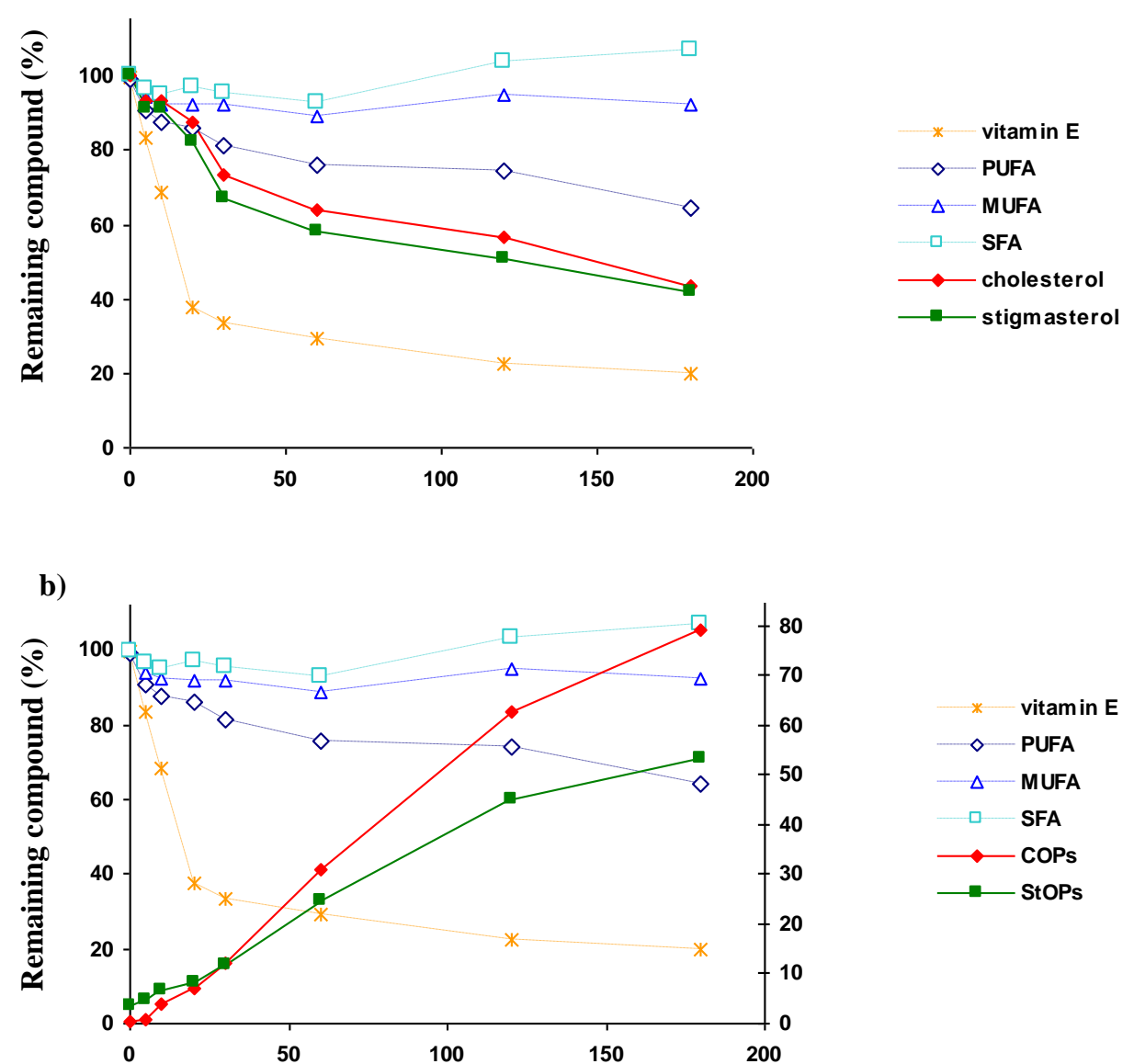

Figure 3. Vitamin E, PUFA (polyunsaturated fatty acids), MUFA (monounsaturated fatty acids) and SFA (saturated fatty acids) evolution as compared to sterols degradation (Figure $3 \mathrm{a}$ ) or oxysterols formation (Figure $3 \mathrm{~b}$ ) in the sample along the heating process. COPs: total cholesterol oxidation products; StOPs: total stigmasterol oxidation products. 
Table 1. Individual oxysterols from cholesterol and stigmasterol along the heating process ( $\mu \mathrm{g}$ oxysterol / $\mathrm{mg}$ sterol)

\begin{tabular}{|c|c|c|c|c|c|c|c|c|}
\hline & \multicolumn{8}{|c|}{ time (min) } \\
\hline & $\mathbf{0}$ & 5 & 10 & 20 & 30 & 60 & 120 & 180 \\
\hline \multicolumn{9}{|c|}{ COPs (Cholesterol oxidation products) } \\
\hline $7 \alpha-\mathrm{HC}$ & $0.02 \pm 0.01$ & $0.07 \pm 0.00$ & $0.64 \pm 0.12$ & $1.32 \pm 0.13$ & $2.31 \pm 0.06$ & $6.44 \pm 0.42$ & $13.98 \pm 0.69$ & $20.24 \pm 0.94$ \\
\hline 7ß-HC & $0.00 \pm 0.00$ & $0.06 \pm 0.01$ & $0.51 \pm 0.10$ & $1.14 \pm 0.13$ & $2.05 \pm 0.07$ & $5.99 \pm 0.55$ & $12.46 \pm 0.65$ & $17.58 \pm 0.63$ \\
\hline$\beta-E C$ & $0.05 \pm 0.02$ & $0.15 \pm 0.01$ & $0.95 \pm 0.14$ & $1.59 \pm 0.09$ & $2.80 \pm 0.13$ & $7.33 \pm 0.56$ & $14.84 \pm 1.20$ & $12.44 \pm 0.41$ \\
\hline$\alpha-\mathbf{E C}$ & $0.13 \pm 0.02$ & $0.18 \pm 0.00$ & $0.91 \pm 0.10$ & $1.54 \pm 0.12$ & $2.51 \pm 0.21$ & $6.09 \pm 0.41$ & $10.48 \pm 0.90$ & $6.84 \pm 0.37$ \\
\hline CT & $0.00 \pm 0.00$ & $0.02 \pm 0.00$ & $0.04 \pm 0.01$ & $0.10 \pm 0.02$ & $0.11 \pm 0.00$ & $0.25 \pm 0.05$ & $0.45 \pm 0.00$ & $0.62 \pm 0.08$ \\
\hline 25-HC & $0.16 \pm 0.02$ & $0.00 \pm 0.00$ & $0.00 \pm 0.00$ & $0.11 \pm 0.00$ & $0.16 \pm 0.01$ & $0.35 \pm 0.03$ & $1.29 \pm 0.18$ & $1.79 \pm 0.23$ \\
\hline 7-KC & $0.11 \pm 0.06$ & $0.33 \pm 0.02$ & $1.07 \pm 0.17$ & $1.45 \pm 0.18$ & $2.03 \pm 0.14$ & $4.38 \pm 0.45$ & $9.28 \pm 1.00$ & $19.51 \pm 4.66$ \\
\hline \multicolumn{9}{|c|}{ StOPs (Stigmasterol oxidation products) } \\
\hline $7 \alpha-H S$ & $0.39 \pm 0.02$ & $0.51 \pm 0.00$ & $0.95 \pm 0.08$ & $1.44 \pm 0.08$ & $2.17 \pm 0.04$ & $5.02 \pm 0.36$ & $9.94 \pm 0.45$ & $14.08 \pm 0.78$ \\
\hline 7ß-HS & $0.36 \pm 0.08$ & $0.60 \pm 0.00$ & $1.02 \pm 0.07$ & $1.55 \pm 0.10$ & $2.28 \pm 0.06$ & $5.34 \pm 0.39$ & $10.03 \pm 0.52$ & $13.62 \pm 0.88$ \\
\hline$\beta$-ES & $0.40 \pm 0.15$ & $0.57 \pm 0.03$ & $1.12 \pm 0.11$ & $1.52 \pm 0.08$ & $2.37 \pm 0.10$ & $5.59 \pm 0.44$ & $10.19 \pm 0.86$ & $7.47 \pm 0.60$ \\
\hline$\alpha-E S$ & $0.39 \pm 0.14$ & $0.46 \pm 0.00$ & $0.95 \pm 0.09$ & $1.25 \pm 0.15$ & $1.88 \pm 0.14$ & $3.93 \pm 0.13$ & $6.53 \pm 0.84$ & $3.25 \pm 0.42$ \\
\hline ST & $0.10 \pm 0.03$ & $0.14 \pm 0.00$ & $0.15 \pm 0.01$ & $0.15 \pm 0.01$ & $0.19 \pm 0.01$ & $0.27 \pm 0.01$ & $0.43 \pm 0.04$ & $0.49 \pm 0.09$ \\
\hline 25-HS & $0.00 \pm 0.00$ & $0.00 \pm 0.00$ & $0.00 \pm 0.00$ & $0.00 \pm 0.00$ & $0.00 \pm 0.00$ & $0.00 \pm 0.00$ & $0.00 \pm 0.00$ & $0.00 \pm 0.00$ \\
\hline 7-KS & $1.88 \pm 0.39$ & $2.32 \pm 0.04$ & $2.37 \pm 0.15$ & $2.39 \pm 0.06$ & $2.70 \pm 0.05$ & $4.33 \pm 0.29$ & $7.69 \pm 0.73$ & $14.43 \pm 2.25$ \\
\hline
\end{tabular}


Table 2. Content on vitamin E (mg / $100 \mathrm{~g}$ ) and fatty acids (g / $100 \mathrm{~g}$ ) along the heating process. Different letters denote statistical differences $(\mathrm{p}<0.05)$ along time.

\begin{tabular}{|c|c|c|c|c|c|c|c|c|}
\hline & \multicolumn{8}{|c|}{ time (min) } \\
\hline & $\mathbf{0}$ & 5 & 10 & 20 & 30 & 60 & 120 & 180 \\
\hline Vitamin E & $71.09 \pm 0.83 \mathrm{a}$ & $59.21 \pm 8.71 \mathrm{~b}$ & $48.67 \pm 2.55 \mathrm{~b}$ & $26.79 \pm 4.89 \mathrm{c}$ & $23.79 \pm 4.40 \mathrm{~cd}$ & $20.81 \pm 4.71 \mathrm{~cd}$ & $16.10 \pm 1.11 \mathrm{~cd}$ & $14.24 \pm 1.62 \mathrm{~d}$ \\
\hline Palmitic & $6.30 \pm 0.72 \mathrm{a}$ & $6.04 \pm 0.09 \mathrm{a}$ & $6.00 \pm 0.14 \mathrm{a}$ & $6.15 \pm 0.20 \mathrm{a}$ & $6.05 \pm 0.28 \mathrm{a}$ & $6.01 \pm 0.11 \mathrm{a}$ & $6.48 \pm 0.23 \mathrm{a}$ & $6.96 \pm 0.01 \mathrm{a}$ \\
\hline t-Palmitoleic & $0.02 \pm 0.01 \mathrm{a}$ & $0.03 \pm 0.00 \mathrm{a}$ & $0.03 \pm 0.00 \mathrm{a}$ & $0.03 \pm 0.00 \mathrm{a}$ & $0.05 \pm 0.03 \mathrm{a}$ & $0.03 \pm 0.00 \mathrm{a}$ & $0.03 \pm 0.00 \mathrm{a}$ & $0.04 \pm 0.00 \mathrm{a}$ \\
\hline Palmitoleic & $0.11 \pm 0.03 \mathrm{a}$ & $0.04 \pm 0.00 \mathrm{~b}$ & $0.05 \pm 0.00 \mathrm{~b}$ & $0.05 \pm 0.01 \mathrm{~b}$ & $0.04 \pm 0.00 \mathrm{~b}$ & $0.05 \pm 0.01 \mathrm{~b}$ & $0.05 \pm 0.00 \mathrm{~b}$ & $0.06 \pm 0.00 \mathrm{~b}$ \\
\hline Stearic & $4.08 \pm 0.26 \mathrm{a}$ & $3.61 \pm 0.04 \mathrm{ab}$ & $3.55 \pm 0.11 \mathrm{~b}$ & $3.62 \pm 0.13 \mathrm{ab}$ & $3.64 \pm 0.15 \mathrm{ab}$ & $3.56 \pm 0.13 b$ & $3.97 \pm 0.05 \mathrm{a}$ & $4.15 \pm 0.04 \mathrm{a}$ \\
\hline Elaidic & $0.27 \pm 0.13 \mathrm{a}$ & $0.02 \pm 0.00 \mathrm{~b}$ & $0.02 \pm 0.00 \mathrm{~b}$ & $0.02 \pm 0.00 \mathrm{~b}$ & $0.02 \pm 0.00 \mathrm{~b}$ & $0.02 \pm 0.00 \mathrm{~b}$ & $0.02 \pm 0.00 \mathrm{~b}$ & $0.03 \pm 0.00 \mathrm{~b}$ \\
\hline Oleic & $23.71 \pm 0.93 \mathrm{a}$ & $22.45 \pm 0.08 \mathrm{ab}$ & $21.91 \pm 0.35 \mathrm{~b}$ & $21.83 \pm 0.64 \mathrm{~b}$ & $21.83 \pm 0.56 \mathrm{~b}$ & $21.10 \pm 0.48 \mathrm{~b}$ & $22.50 \pm 0.46 \mathrm{~b}$ & $21.91 \pm 0.38 \mathrm{~b}$ \\
\hline Vaccenic & $0.74 \pm 0.11 \mathrm{a}$ & $0.73 \pm 0.00 \mathrm{a}$ & $0.66 \pm 0.08 \mathrm{a}$ & $0.68 \pm 0.10 \mathrm{a}$ & $0.58 \pm 0.08 \mathrm{a}$ & $0.30 \pm 0.03 \mathrm{~b}$ & $0.70 \pm 0.01 \mathrm{a}$ & $0.34 \pm 0.02 b$ \\
\hline t-Linoleic & $0.12 \pm 0.03 \mathrm{ab}$ & $0.05 \pm 0.00 \mathrm{~b}$ & $0.20 \pm 0.01 \mathrm{a}$ & $0.13 \pm 0.02 \mathrm{ab}$ & $0.11 \pm 0.07 \mathrm{ab}$ & $0.09 \pm 0.01 \mathrm{ab}$ & $0.12 \pm 0.02 \mathrm{ab}$ & $0.19 \pm 0.04 \mathrm{a}$ \\
\hline c-t linoleic & $0.21 \pm 0.02 \mathrm{a}$ & $0.20 \pm 0.00 \mathrm{a}$ & $0.22 \pm 0.03 \mathrm{a}$ & $0.21 \pm 0.01 \mathrm{a}$ & $0.20 \pm 0.03 \mathrm{a}$ & $0.20 \pm 0.02 \mathrm{a}$ & $0.20 \pm 0.01 \mathrm{a}$ & $0.22 \pm 0.01 \mathrm{a}$ \\
\hline t-c linoleic & $0.20 \pm 0.06 \mathrm{a}$ & $0.21 \pm 0.00 \mathrm{ab}$ & $0.22 \pm 0.01 \mathrm{ab}$ & $0.22 \pm 0.01 \mathrm{ab}$ & $0.21 \pm 0.01 \mathrm{ab}$ & $0.22 \pm 0.02 \mathrm{ab}$ & $0.22 \pm 0.01 \mathrm{ab}$ & $0.25 \pm 0.02 \mathrm{~b}$ \\
\hline Linoleic & $63.45 \pm 3.38 \mathrm{a}$ & $57.50 \pm 0.40 \mathrm{ab}$ & $55.41 \pm 1.12 \mathrm{bc}$ & $54.34 \pm 1.21 \mathrm{bc}$ & $51.35 \pm 3.80 \mathrm{~cd}$ & $47.85 \pm 0.75 \mathrm{~d}$ & $46.93 \pm 0.98 \mathrm{~d}$ & $40.50 \pm 0.88 \mathrm{e}$ \\
\hline$\gamma$-linolenic & $0.05 \pm 0.03 \mathrm{a}$ & $0.01 \pm 0.00 \mathrm{a}$ & $0.01 \pm 0.00 \mathrm{a}$ & $0.01 \pm 0.00 \mathrm{a}$ & $0.01 \pm 0.00 \mathrm{a}$ & $0.01 \pm 0.00 \mathrm{a}$ & $0.01 \pm 0.00 \mathrm{a}$ & $0.02 \pm 0.00 \mathrm{a}$ \\
\hline Eicosenoic & $0.09 \pm 0.02 \mathrm{a}$ & $0.01 \pm 0.00 \mathrm{~b}$ & $0.08 \pm 0.00 \mathrm{a}$ & $0.09 \pm 0.00 \mathrm{a}$ & $0.09 \pm 0.00 \mathrm{a}$ & $0.09 \pm 0.01 \mathrm{a}$ & $0.09 \pm 0.01 \mathrm{a}$ & $0.08 \pm 0.02 \mathrm{a}$ \\
\hline$\alpha$-linolenic & $0.07 \pm 0.01 \mathrm{a}$ & $0.06 \pm 0.02 \mathrm{a}$ & $0.06 \pm 0.00 \mathrm{a}$ & $0.06 \pm 0.00 \mathrm{a}$ & $0.06 \pm 0.01 \mathrm{a}$ & $0.05 \pm 0.01 \mathrm{ab}$ & $0.04 \pm 0.00 \mathrm{~b}$ & $0.03 \pm 0.00 \mathrm{~b}$ \\
\hline
\end{tabular}


Table 3. Correlations between sterols or total oxysterols and vitamin E, PUFA (polyunsaturated fatty acids), MUFA (monounsaturated fatty acids) and SFA (saturated fatty acids), along the heating process. R denotes Pearson coefficient and $\mathrm{P}$ denotes $\mathrm{P}$ value (statistical significance).

\begin{tabular}{ccccccccc}
\hline & \multicolumn{2}{c}{ vitamin E } & \multicolumn{2}{c}{ PUFA } & \multicolumn{2}{c}{ MUFA } & \multicolumn{2}{c}{ SFA } \\
\cline { 2 - 8 } & R & P & R & P & R & P & R & P \\
\hline cholesterol & 0.8535 & 0.0000 & 0.9449 & 0.0000 & 0.3508 & 0.0935 & -0.5127 & 0.0140 \\
stigmasterol & 0.8929 & 0.0000 & 0.9345 & 0.0000 & 0.3877 & 0.0615 & -0.4538 & 0.0259 \\
COPs $^{\text {a }}$ & -0.7248 & 0.0001 & -0.8855 & 0.0000 & -0.1924 & 0.3697 & 0.6817 & 0.0002 \\
StOPs $^{\text {b }}$ & -0.7325 & 0.0000 & -0.8889 & 0.0000 & -0.2092 & 0.3282 & 0.6642 & 0.0004 \\
\hline
\end{tabular}

\footnotetext{
${ }^{a}$ Total cholesterol oxidation products
}

b Total stigmasterol oxidation products 


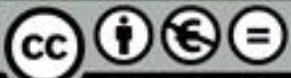

BY NC ND Esta obra está bajo una licencia de Creative Commons Reconocimiento-

NoComercial-SinObraDerivada 4.0 Internacional. 